\title{
Observation of Bi Coarsening and Dissolution Behaviors in Melting Al-Bi Immiscible Alloy
}

\author{
Wen-Quan $\mathrm{Lu}^{1,2} \cdot$ Shu-Guang Zhang ${ }^{1} \cdot$ Jian-Guo $\mathbf{L i}^{1}$
}

Received: 2 March 2016/Revised: 17 May 2016/Published online: 7 July 2016

(C) The Chinese Society for Metals and Springer-Verlag Berlin Heidelberg 2016

\begin{abstract}
Using synchrotron radiography, a melting process of the $\mathrm{Al}-10 \mathrm{wt} \% \mathrm{Bi}$ immiscible alloy was fully observed, and Bi solute coarsening and dissolution behaviors as well as their effect on the microstructural evolution were also investigated. We found that two different steps including coarsening and dissolution processes can be used to describe the structure evolution in melting Al-10 wt\% Bi immiscible alloy. And diffusion coalescence controlled the coalescence of $\mathrm{Bi}$ droplets at the early stage of the melting Al-10 wt\% Bi immiscible alloy, while the coagulation during movement did at later stage. Also, the larger the droplet, the larger the distance of the steady-state concentration distribution around the droplet.
\end{abstract}

KEY WORDS: Immiscible alloy; Coarsening; Dissolution; Synchrotron radiography

\section{Introduction}

Solute dissolution is commonly seen in almost all the natural scientific fields and is mainly related to metal materials are mineral purification [1], corrosion science [2] and materials processing [3]. For example, Fu et al. [1] found that the dissolution behavior of calcium chromates in acid or alkali solution plays a key role in extracting chromium. Peng et al. [3] reported that during severe plastic deformation in $\mathrm{Al}-\mathrm{Cu}$ alloy, $\theta^{\prime \prime}$ and $\theta^{\prime}$ phases are dissolved at subboundaries and shear bands, and surface tension can promote their

Available online at http://link.springer.com/journal/40195

Shu-Guang Zhang

sgzhang@sjtu.edu.cn

$\triangle$ Jian-Guo Li

lijg@sjtu.edu.cn

1 School of Materials Science and Engineering, Shanghai Jiao Tong University, Shanghai 200240, China

2 School of Environmental Science and Engineering, Shanghai Jiao Tong University, Shanghai 200240, China dissolution processes. Besides the above-mentioned fields, as most of metal materials are inhomogeneous, their melting processes are accompanied by solute dissolution unavoidably. However, although melting is one of most important phase transformation process, it is very far from getting extensive attention.

With respect to $\mathrm{Al}-\mathrm{Bi}$ immiscible alloy, it can be used as self-lubricating bearings or electronic solders if the alloy forms suitable microstructure [4-6]. So, in order to develop its applications, considerable efforts have been dedicated to investigate the solidification and electrochemical behaviors of the Al-Bi alloy. For instance, Ratke et al. [4] reported that both strings of pearls and fibers arranged $\mathrm{Bi}$ phase appear in $\mathrm{Al}$ matrix after directional solidification. Osório et al. $[7,8]$ found that the electrochemical behavior of the $\mathrm{Al}-\mathrm{Bi}$ alloys is determined by the size of $\mathrm{Bi}$ particle and cell spacing, and the smaller droplet size and finer interphase spacing tend to lower the corrosion resistance. However, as the system of Al-Bi has a wide miscibility gap in the liquid phase, when a homogeneous Al-Bi melt cools into the gap, it will separate into two immiscible liquids with difference in density and composition, and the phase with small volume fraction always generates in a form of 
liquid globule $[9,10]$. Many studies have been carried out to investigate the liquid phase separation process. For example, we recently found that, besides Marangoni motion, Soret effect can also provide a driving force for solute segregation $[9,10]$. Ma et al. [11] reported that the $\mathrm{Bi}$-rich core and the CuSn-rich shell in $\mathrm{Cu}-\mathrm{Sn}-\mathrm{Bi}$ immiscible alloy can be altered by varying composition. Shi et al. [12] reported that volume fraction and surface tension of the separated phases control the final solidification structure in $\mathrm{Fe}-\mathrm{Cu}$ alloy. And in consideration of this phase separation characteristic, the composites with two-, threeand five-layer core-shell structure were synthesized by Wei et al. [13, 14] under reduced gravity condition.

However, most of the previous works on solute coarsening behavior were carried out on solidifying immiscible alloys, but only few researches focused on the melting process of the immiscible alloys [15]. In this wok, we investigated the melting behavior and microstructural evolution of the $\mathrm{Al}-10 \mathrm{wt} \% \mathrm{Bi}$ alloys during the heating process by synchrotron radiography. Bi solution coarsening mechanism was also analyzed.

\section{Experimental}

The $\mathrm{Al}-10 \mathrm{wt} \% \mathrm{Bi}$ alloy particles were prepared from pure $\mathrm{Al}(99.99 \%)$ and $\mathrm{Bi}(99.99 \%)$ by spraying liquid $\mathrm{Al}-10 \mathrm{wt} \%$ Bi alloy into silicone oil placed $40 \mathrm{~mm}$ below the sample. As the liquid alloy jet forms several hundred liquid alloy spheres with different sizes and these droplets fall freely into silicon oil, it is very difficult to measure the droplet temperature directly within the short falling time. Furthermore, as the falling distance is very short (here is only $40 \mathrm{~mm}$ ), the solidification process mainly occurs in the silicon oil. So, the gravity level during solidification is conventional gravity.

The imaging experimental device configuration at Shanghai synchrotron radiation facility (SSRF) was described elsewhere [16]. A sample $(\sim 2.1 \mathrm{~mm}$ in diameter) was placed on a $\mathrm{MgO}$ single crystal sheet in furnace. The furnace chamber was backfilled with argon after evacuation to $6 \times 10^{-4} \mathrm{~Pa}$. The specimen was heated from top by a $\mathrm{CO}_{2}$ laser, and its temperature was measured by an infrared thermometer. The X-ray beam, monochromatized to $34 \mathrm{keV}$, passed through the sample and generated an absorption radiograph which was captured by a chargecoupled device (CCD) detector with the spatial resolution of $9 \mu \mathrm{m} /$ pixel. The applied temporal resolution is $0.016 \mathrm{~s}$ per frame.

\section{Results and Discussion}

Figure 1 shows a sequence of synchrotron radiography images of the melting $\mathrm{Al}-10 \mathrm{wt} \% \mathrm{Bi}$ alloy with the heating rate of $4.4 \mathrm{~K} / \mathrm{s}$. Bi phase appears in dark gray, while $\mathrm{Al}$ matrix exhibits light contrast. Most of Bi phase appears at the center of the original solidified alloy (Fig. 1a). As the melting point of $\mathrm{Bi}\left(271^{\circ} \mathrm{C}\right)$ is lower than that of $\mathrm{Al}$

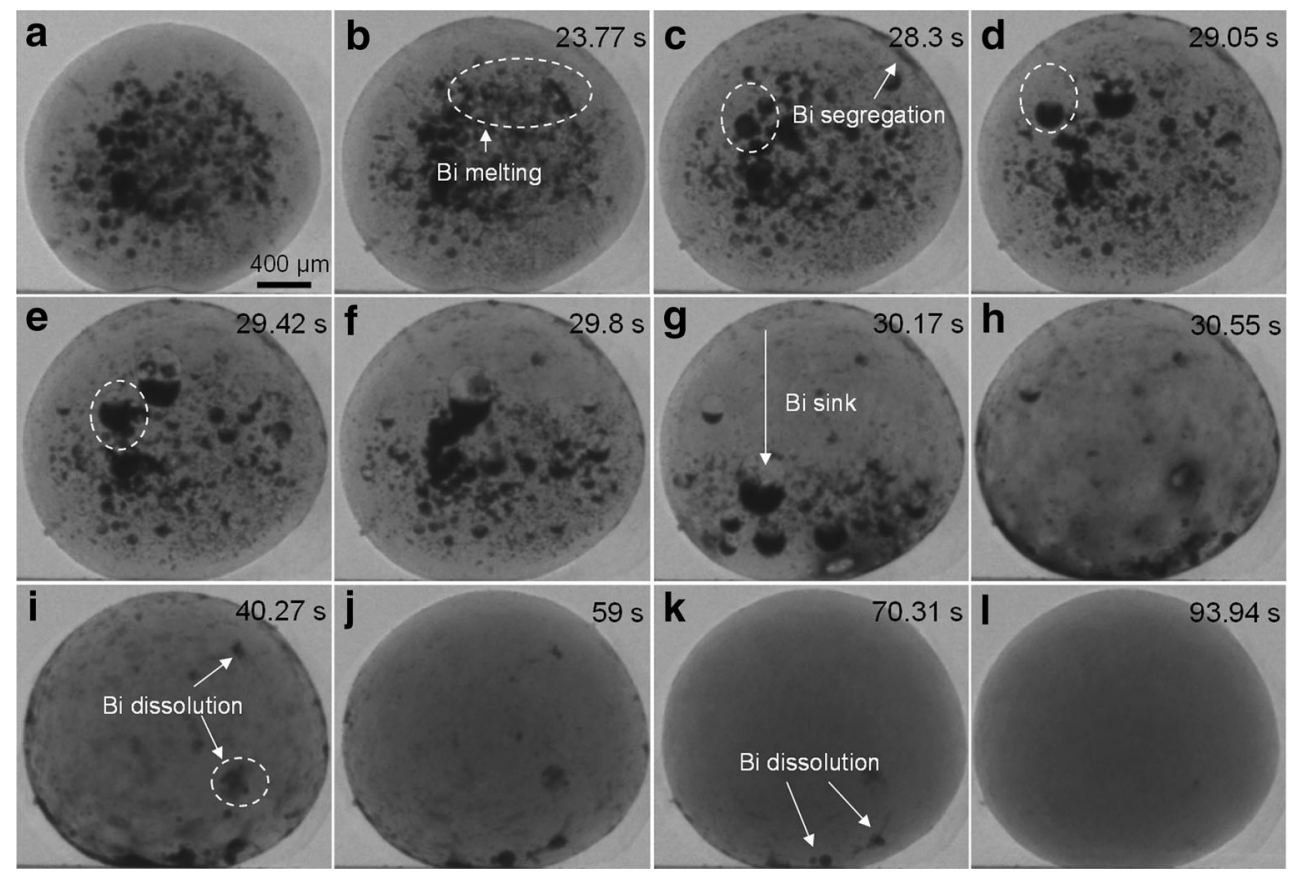

Fig. 1 a Original structure of Al-10 wt $\%$ Bi alloy particle before melting, b-l Microstructural evolution in melting Al-10 wt\% Bi immiscible alloy. The Bi phase exhibits dark gray, while the Al matrix phase shows light contrast 
$\left(660^{\circ} \mathrm{C}\right)$, Bi-rich phase is melted firstly with increasing temperature as circled in Fig. 1b. And Bi-rich phase is released gradually surrounding solid $\mathrm{Al}$ during liquefaction process, accompanying surface segregation, coagulation and sinking of the Bi-rich regions (Fig. 1b-h). Meanwhile, some minor Bi phase still floats in matrix melt (Fig. 1g-i). And they all dissolve into Al matrix melt eventually at high temperature (Fig. 11).

Unlike bubble evolution during superheating Al-Ca alloy melts [16, 17], the structural evolution of melting Al$10 \mathrm{wt} \% \mathrm{Bi}$ alloy can be described by two different steps: coarsening and dissolution processes. As seen in Fig. 1a, a large amount of $\mathrm{Bi}$ particles dispersed in the original microstructure, the size of the Bi particles is small, and thus they have large specific surface area and are in a thermodynamic instability state. So, it is a spontaneous process to decrease its specific surface area by diffusion coalescence $[18,19]$. According to Lifshitz-Slyozov-Wagner (LSW) theory [19-21], the exponent of the power law for the evolution of the average droplets radius is independent of composition and volume fraction, and the growth law of the average droplets radius can be described as

$\overline{r(t)}^{3}-{\overline{r_{0}}}^{3}=K_{\mathrm{lsw}} t$,

with the abbreviation:

$K_{\mathrm{lsw}}=\frac{8}{9} \frac{D \gamma V \mathrm{c}_{\infty}}{k_{\mathrm{B}} T\left(c_{\beta}-c_{\infty}\right)}$,

where $\overline{r_{0}}$ and $\overline{r(t)}$ are the average radii of minor droplets at the beginning of coarsening and at time $t, K_{\mathrm{lsw}}$ is the coarsening rate constant, $D$ is the diffusion coefficient, $\gamma$ is the interfacial tension, $V$ the atomic volume, $k_{\mathrm{B}}$ is the Boltzmann constant, $c_{\infty}$ is the equilibrium concentration, $\mathrm{c}_{\beta}$ is the concentration of solute within the dispersed phase. From Eq. (1), for diffusion-controlled coalescence process, the cube power of the average radius is proportional to the coarsening time.

Besides the diffusion coalescence mode, the Bi-rich droplets can also collide with each other during movement. As the temperature gradient between the center of the sample and its periphery can be negligible (the diameter of the $\mathrm{Al}-10 \mathrm{wt} \% \mathrm{Bi}$ alloy sphere is only $2.1 \mathrm{~mm}$, and the heating rate is only $4.4 \mathrm{~K} / \mathrm{s}$ ), the collision and coagulation of $\mathrm{Bi}$ droplets come mainly from the Stokes motion due to the large difference in density between $\mathrm{Bi}\left(9.8 \mathrm{~g} / \mathrm{cm}^{3}\right)$ and Al $\left(2.7 \mathrm{~g} / \mathrm{cm}^{3}\right)$. And the decreased number of Bi droplets due to droplets movement can be written as [9, 19]

$\frac{N(t)}{N_{0}}=\frac{1}{1+W N_{0} \cdot t / 2}$,

where $N_{0}$ and $N(t)$ are the droplet number at $t=0$ and time $t, W$ is the collision volume due to Stokes motion, and it can be calculated by $[9,22]$

$W\left(r_{1}, r_{2}\right)=\pi\left(r_{1}+r_{2}\right)^{2}\left|V_{\mathrm{s}}\left(r_{1}\right)-V_{\mathrm{s}}\left(r_{2}\right)\right|$,

where $r_{1}$ and $r_{2}$ are the radii of two different droplets, $V_{\mathrm{s}}$ is the velocity of Stokes motion, and it can be calculated by [9]:

$V_{\mathrm{s}}=\frac{2 g \Delta \rho}{3 \mu_{\mathrm{m}}} \frac{\mu_{\mathrm{d}}+\mu_{\mathrm{m}}}{3 \mu_{\mathrm{d}}+2 \mu_{\mathrm{m}}} r^{2}$,

where $g$ is the gravity coefficient; $\Delta \rho$ is the difference of density between the Bi droplet and matrix; $r$ is the droplet radius; $\mu_{\mathrm{d}}$ and $\mu_{\mathrm{m}}$ are the viscosities of the $\mathrm{Bi}$ droplet and $\mathrm{Al}$ matrix, respectively; Since the total volume $(\Phi)$ of the Bi droplets is not changed by the collision and coagulation $[9,19]$. Thus,

$\Phi=\frac{4}{3} \pi{\overline{r_{0}}}^{3} N_{0}=\frac{4}{3} \pi \overline{r(t)}^{3} N(t)$.

So, according to Eqs. (3) and (6), the change in the mean droplet radius due to Stokes motion can be described as

$\overline{r(t)}^{3}-{\overline{r_{0}}}^{3}=\frac{1}{2} N_{0}{\overline{r_{0}}}^{3} W t=K_{\mathrm{s}} t$.

Figure 2 shows the cube of the average droplets radius plot against time with the parameters presented in Table 1. From Fig. 2, when the droplet radius is small, the coarsening degree that caused by diffusion coalescence is larger than that caused by Stokes motion. When the droplet radius becomes large, the coarsening degree caused by Stokes
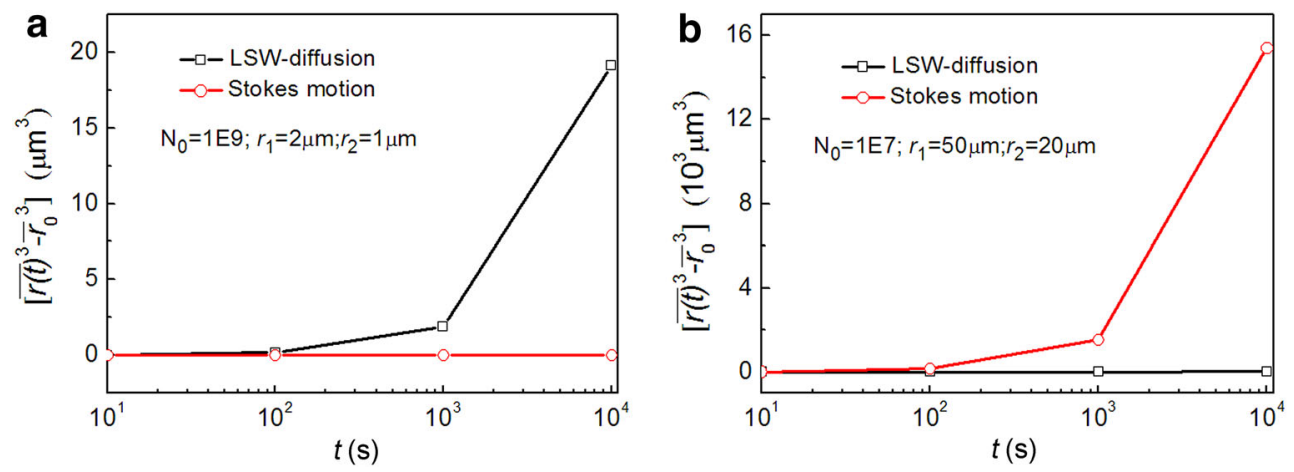

Fig. 2 Cube of the average droplets radius against time 
Table 1 Parameters used in calculation

\begin{tabular}{lll}
\hline Parameters & Values & References \\
\hline Gravity coefficient, $g$ & $9.8 \mathrm{~m} / \mathrm{s}^{2}$ & \\
Density of matrix, $\rho_{\mathrm{m}}$ & $2.8 \times 10^{3} \mathrm{~kg} / \mathrm{m}^{3}$ & {$[9]$} \\
Density of Bi droplet, $\rho_{\mathrm{d}}$ & $9.8 \times 10^{3} \mathrm{~kg} / \mathrm{m}^{3}$ & {$[9]$} \\
Viscosity of matrix, $\mu_{\mathrm{m}}$ & $1.903 \times 10^{-3} \mathrm{~Pa} \mathrm{~s}$ & {$[9]$} \\
Viscosity of Bi droplet, $\mu_{\mathrm{d}}$ & $2.13 \times 10^{-3} \mathrm{~Pa} \mathrm{~s}$ & {$[9]$} \\
Interfacial tension, $\gamma$ & $7.35 \times 10^{-2} \mathrm{~N} / \mathrm{m}$ & {$[13]$} \\
Diffusion coefficient of Bi & $2.36 \times 10^{-5} \mathrm{~cm}^{2} / \mathrm{s}$ & {$[14]$} \\
$\quad$ solute in Al matrix, $D$ & & \\
\hline
\end{tabular}

motion is larger than that by diffusion coalescence. This indicates that diffusion coalescence controls the coalescence of the droplets at the early stage of melting $\mathrm{Al}-10 \mathrm{wt} \% \mathrm{Bi}$ immiscible alloy, while the coagulation during movement do at later stage.

As the movement activity of $\mathrm{Bi}$ atoms strengthens gradually with the increase in the temperature and also the Bi solute concentration in $\mathrm{Al}$ matrix melt increases, Bi phase dissolves into $\mathrm{Al}$ matrix melt gradually. So, the coalescence process is replaced by dissolution process with increasing temperature. Once a Bi droplet has melted, it acts as an effective increase for $\mathrm{Bi}$ solute diffusion, leading to local enrichment of Bi solute in a region with a radius of approximately $l_{\mathrm{D}}$. And the characteristic time that formed a steady-state concentration distribution around each droplet can be described by $t^{*}\left(=r^{2} / D\right)$, where $r$ is the droplet radius, $D$ is the diffusion coefficient of Bi solute in $\mathrm{Al}$ matrix. According to Stokes-Einstein formula [14], the diffusion coefficient of Bi solute in Al matrix is equal to $2.36 \times 10^{-5} \mathrm{~cm}^{2} / \mathrm{s}$ at $1000 \mathrm{~K}$. When $r_{1}=10 \mu \mathrm{m}$ and $r_{2}=20 \mu \mathrm{m}, t^{*}$ is equal to 0.042 and $0.17 \mathrm{~s}$, respectively. Therefore, for two different size droplets, the characteristic time is different. So, the distances of the steady-state concentration distribution $\left(l_{\mathrm{D}}\right)$ are different for different size

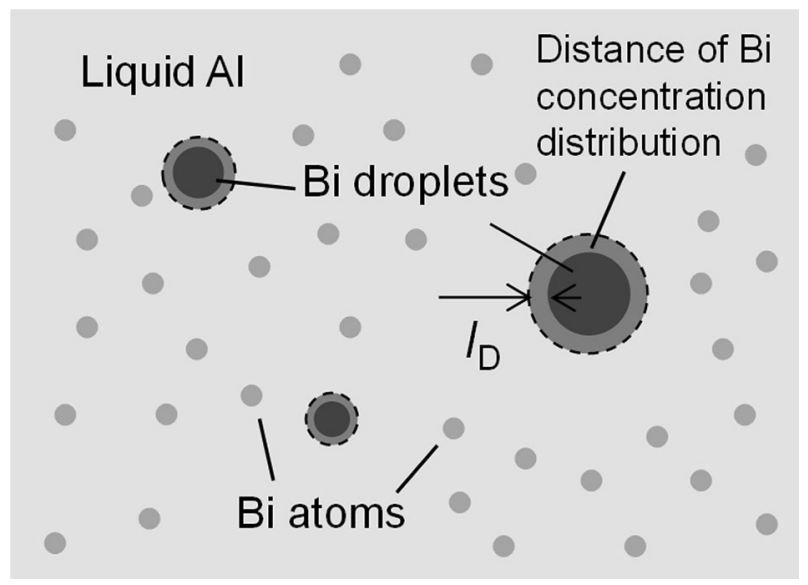

Fig. 3 Sketch of dissolution process of Bi droplets. $l_{\mathrm{D}}$ is the distance of the steady-state concentration distribution around $\mathrm{Bi}$ droplet droplets. And the larger the droplet, the larger the distance of the steady-state concentration distribution as shown in Fig. 3.

\section{Conclusions}

In summary, we have direct observed the $\mathrm{Al}-10 \mathrm{wt} \% \mathrm{Bi}$ alloy melting process by synchrotron radiography. The structure evolution in melting $\mathrm{Al}-10 \mathrm{wt} \% \mathrm{Bi}$ immiscible alloy can be described by $\mathrm{Bi}$ coarsening and dissolution process. Bi droplet coarsening was dominated diffusion coalescence at the early stage of the melting $\mathrm{Al}-10 \mathrm{wt} \% \mathrm{Bi}$ immiscible alloy, while the effect of the coagulation during movement was strengthened at later stage. Also, the distances of the steady-state concentration distribution around droplets are different for different size droplets.

Acknowledgments We thank the BL13W1 beam line station of SSRF for providing the beam time and Mr. Zhiyong Dai as well as Mr. Mingqin $\mathrm{Xu}$ for their help with experiments. This work was supported by the National Natural Science Foundation of China (Nos. 51374144, 51271119 and 51574165), Shanghai Municipal Natural Science Foundation (13ZR1420600) and Shanghai Rising-Star Program (14QA1402300).

\section{References}

[1] N.X. Fu, W.L. Zhang, L.N. Zhang, X.H. Du, Z.T. Sui, J. Shenyang Univ. Technol. 34, 639 (2012)

[2] B. Bozzini, C. Lenardi, M. Serra, A. Fanigliulo, Br. Corros. J. 37, 173 (2002)

[3] B.S. Peng, N.A. Lin, Z.Y. Liu, X.C. Xu, S.S. Jiang, S.M. Zeng, Chin. J. Nonferrous Met. 19, 874 (2009)

[4] L. Ratke, A. Müller, Scr. Mater. 54, 1217 (2006)

[5] H.J. Kang, P. Zhou, F. Cao, J. Zhu, Y.N. Fu, W.X. Huang, T.Q. Xiao, T.M. Wang, Acta Metall. Sin. (Engl. Lett.) 28, 940 (2015)

[6] P.L. Schaffer, R.H. Mathiesen, L. Arnberg, M.D. Sabatino, A. Snigirev, New J. Phys. 10, 1 (2008)

[7] W.R. Osório, E.S. Freitas, A. Garcia, Electrochim. Acta 108, 781 (2013)

[8] W.R. Osório, E.S. Freitas, A. Garcia, J. Mater. Eng. Perform. 23, 333 (2014)

[9] W.Q. Lu, S.G. Zhang, J.G. Li, Mater. Lett. 107, 340 (2013)

[10] W.Q. Lu, S.G. Zhang, J.G. Li, Appl. Phys. A 117, 787 (2014)

[11] B.Q. Ma, J.Q. Li, Z.J. Peng, G.C. Zhang, J. Alloys Compd. 535, 95 (2012)

[12] R.P. Shi, Y. Wang, C.P. Wang, X.J. Liu, Appl. Phys. Lett. 98, 204106 (2011)

[13] W.L. Wang, Z.Q. Li, B. Wei, Acta Mater. 59, 5482 (2011)

[14] B.C. Luo, X.R. Liu, B. Wei, J. Appl. Phys. 106, 053523 (2009)

[15] A. Clarke, S. Imhoff, P. Gibbs, J. Cooley, C. Morris, F. Merrill, B. Hollander, F. Mariam, T. Ott, M. Barker, Sci. Rep. 3, 2020 (2013)

[16] W.Q. Lu, S.G. Zhang, W. Zhang, G. Kaptay, J.D. Yu, Y.N. Fu, J.G. Li, Scr. Mater. 102, 19 (2015)

[17] S.G. Zhang, L. Zhang, W.Q. Lu, W. Zhang, J.D. Yu, Y.N. Fu, J.G. Li, Appl. Phys. Lett. 103, 164103 (2013)

[18] W. Bender, L. Ratke, Acta Mater. 46, 1125 (1998)

[19] L. Ratke, Mater. Sci. Eng. A 203, 399 (1995)

[20] I.M. Lifshitz, V.V. Slezhov, J. Phys. Chem. Solids 19, 35 (1961)

[21] C. Wagner, Z. Elektrochem. 65, 581 (1961)

[22] J.Z. Zhao, H.L. Li, L. Zhao, Acta Metall. Sin. 45, 1435 (2009). (in Chinese) 